Review

\title{
The Changing Epidemiology of Kunjin Virus in Australia
}

\author{
Natalie A. Prow ${ }^{1,2}$
}

1 Australian Infectious Diseases Research Centre, University of Queensland, St Lucia, QLD, 4072, Australia; E-Mail: n.prow@uq.edu.au; Tel.: +61-7-3365-4648; Fax: +61-7-3365-4620

2 School of Chemistry and Molecular Biosciences, University of Queensland, St Lucia, QLD, 4072, Australia

Received: 24 September 2013; in revised form: 4 November 2013 / Accepted: 7 November 2013 / Published: 25 November 2013

\begin{abstract}
West Nile virus (WNV) is a mosquito-borne virus responsible for outbreaks of viral encephalitis in humans and horses, with particularly virulent strains causing recent outbreaks of disease in Eastern Europe, the Middle East and North America. A strain of $\mathrm{WNV}$, Kunjin ( $\left.\mathrm{WNV}_{\mathrm{KUN}}\right)$, is endemic in northern Australia and infection with this virus is generally asymptomatic. However in early 2011, an unprecedented outbreak of encephalitis in horses occurred in south-eastern Australia, resulting in mortality in approximately $10 \%-15 \%$ of infected horses. A WNV-like virus $\left(\mathrm{WNV}_{\mathrm{NSW} 2011}\right)$ was isolated and found to be most closely related to the indigenous $\mathrm{WNV}_{\mathrm{KUN}}$, rather than other exotic WNV strains. Furthermore, at least two amino acid changes associated with increased virulence of the North American New York 99 strain $\left(\mathrm{WNV}_{\mathrm{NY} 99}\right)$ compared to the prototype $\mathrm{WNV}_{\mathrm{KUN}}$ were present in the $\mathrm{WNV}_{\mathrm{NSW} 2011}$ sequence. This review summarizes our current understanding of $\mathrm{WNV}_{\mathrm{KUN}}$ and how the epidemiology and ecology of this virus has changed. Analysis of virulence determinants of contemporary $\mathrm{WNV}_{\mathrm{KUN}}$ isolates will provide clues on where virulent strains have emerged in Australia. A better understanding of the changing ecology and epidemiology associated with the emergence of virulent strains is essential to prepare for future outbreaks of WNV disease in Australia.
\end{abstract}

Keywords: West Nile virus; Kunjin virus; epidemiology; Australia 


\section{Introduction}

West Nile virus (WNV) has emerged as a global public health concern, causing large outbreaks in the Americas, Europe and more recently Australia [1-9]. Kunjin virus $\left(\mathrm{WNV}_{\mathrm{KUN}}\right)$ is classified within a clade of the WNV group and has traditionally been associated with mild and rare disease in humans and horses in Australia. Phylogenetic analysis has suggested that WNV emerged in Africa and can be separated into at least seven genetic lineages [10]. There are two main lineages (I and II), with lineage I containing $\mathrm{WNV}_{\mathrm{KUN}}$ isolates and $\mathrm{WNV}$ isolates from North, West and Central Africa; southern and eastern Europe; the Middle East; and New York. Lineage I can be further divided into clade 1a containing $\mathrm{WNV}$ isolates from around the world and the Australian $\mathrm{WNV}_{\mathrm{KUN}}$ isolates forming clade $1 \mathrm{~b}[11]$.

Following extensive flooding across Eastern Australia in 2011 promoting ideal conditions for freshwater mosquito breeding, an unprecedented outbreak of equine encephalitis occurred, leading to the isolation of the first virulent strain of $\mathrm{WNV}_{\mathrm{KUN}}$ to cause a major outbreak, designated $\mathrm{WNV}_{\mathrm{NSW} 2011}$ [2]. For clear distinction throughout this review, $\mathrm{WNV}_{\mathrm{NSW} 2011}$ will be used to describe the virus isolated from New South Wales (NSW) during the 2011 Australian outbreak, and WNV KUN will refer to all other isolates, unless specifically stated otherwise. Prior to this outbreak, there were two Australian $\mathrm{WNV}_{\mathrm{KUN}}$ equine isolates, Boort and 35911. The Boort strain was isolated from the cervical spinal cord of a horse with encephalomyelitis in 1984 from Victoria (VIC), where a small outbreak of unusual equine nervous disease occurred. While other horses in this outbreak displayed similar symptoms, Ross River virus was isolated from a further two horses and these horses did not have detectable antibodies against $\mathrm{WNV}_{\mathrm{KUN}}$ [12]. The 35911 strain was also isolated in 1984 from the Hunter Valley, NSW [13]. There has also been a single human isolate of $\mathrm{WNV}_{\mathrm{KUN}}$, designated Hu6774, from a non-encephalitic patient [10].

This review will summarise what is currently known about the epidemiology and ecology of $\mathrm{WNV}_{\mathrm{KUN}}$ in Australia and how these factors have recently changed. The outbreak in 2011 is an example of how a previously benign virus can evolve to emerge as a new public health threat. The emergence of this new virus has instigated additional studies into the virulence of contemporary strains of $\mathrm{WNV}_{\mathrm{KUN}}$. Possible ecological factors that may have contributed to the unusual epidemiological features of the 2011 outbreak will also be proposed. For a more historical overview of $\mathrm{WNV}_{\mathrm{KUN}}$, the reader is referred to extensive reviews by Hall et al., [14] and Marshall [15].

\section{Ecology and Epidemiology}

\subsection{Vectors and Vertebrate Hosts}

$\mathrm{WNV}_{\mathrm{KUN}}$ is maintained in mosquito-bird transmission cycles, where mosquitoes act as primary vectors and birds as amplifying hosts. Culex $(C x$.) annulirostis, a fresh water mosquito found across Australia, is the principal vector of $\mathrm{WNV}_{\mathrm{KUN}}$ and Murray Valley encephalitis virus (MVEV) in Australia. MVEV co-circulates in the same geographic regions and utilizes the same vectors and vertebrate hosts as $\mathrm{WNV}_{\mathrm{KUN}}$. MVEV remains the only proven cause of fatal human arboviral encephalitis in Australia [16], and causes sporadic outbreaks of encephalitis in humans, mainly in northern Australia. Major outbreaks of MVEV occurred in 1951, 1956, 1974 and in 2000 [17]. For a 
recent clinical review of MVEV in humans, the reader is referred to Knox et al., [18]. MVEV also causes occasional cases of encephalitis in horses [19-21].

Since the first isolation of $\mathrm{WNV}_{\mathrm{KUN}}$, the majority of isolates from field-caught mosquitoes have been from $C x$. annulirostris $[16,22]$. $\mathrm{WNV}_{\mathrm{KUN}}$ has also been occasionally isolated from other mosquito species including Aedes (Ae.) tremulus, Cx. australicus, Cx. squamosus, Ae. alternans, Ae. nomenensis, Ae. vigilax, Anopheles amictus, and Cx. quinquefasciatus [16,22,23]. Horses and humans are generally considered as dead-end hosts, as the resultant viraemia within these species is insufficient to allow further transmission of the virus. Wading birds (particularly Nycticorax calendonicus, the rufous night heron) are considered an important natural reservoir of $\mathrm{WNV}_{\mathrm{KUN}}$. However, a range of birds and mammalian hosts can act as vertebrate hosts for $\mathrm{WNV}_{\mathrm{KUN}}[15,24]$. $\mathrm{WNV}_{\mathrm{KUN}}$ is endemic in northern Australia and has been recorded periodically in south-east Australia through seroconversion in sentinel chickens and human infections [16].

\subsection{Surveillance Using Sentinel Chickens}

The National Arvbovirus and Malaria Advisory Committee (NAMAC) provide expert technical advice on arboviruses to the Australian Health Protection Principal Committee (AHPPC) through the Communicable Diseases Network of Australia (CDNA). NAMAC assists in the detection, management and control of outbreaks of arboviruses and provides advice on the risk of these diseases. The sentinel chicken program provides early warning of arboviral disease activity and allows NAMAC to provide timely warnings on arbovirus activity around Australia. For more details about the sentinel chicken program, NAMAC publish an annual report that can be located on the Australian Government Department of Health and Ageing website [25]. Flocks of sentinel are distributed throughout the Northern Territory (NT), NSW, South Australia (SA), VIC and Western Australia (WA). While the number and location of the flocks may change slightly from year to year, flocks are well distributed to provide valuable information about flavivirus activity in participating states (Figure 1). The program aims to provide early warning of the endemic arboviruses, MVEV and $\mathrm{WNV}_{\mathrm{KUN}}$. This was evident in early 2011 when sentinel chickens in south-eastern Australia widely seroconverted to MVEV and $\mathrm{WNV}_{\mathrm{KUN}}[26]$.

In WA, the sentinel chicken program allows the movements of both $\mathrm{WNV}_{\mathrm{KUN}}$ and MVEV to be tracked [26]. Generally seroconversions are seen to both MVEV and $\mathrm{WNV}_{\mathrm{KUN}}$ each year confirming that these viruses are endemic in northern WA [26-28]. Furthermore, there has been a trend of increasing numbers of seroconversions to $\mathrm{WNV}_{\mathrm{KUN}}$ over several years (1996-2007) [29,30], followed by years with few seroconversions (2008-2009: 2 seroconversions; 2009-2010: 2 seroconverisons). Data from this program would suggest that MVEV is more active in the Kimberley region whereas $\mathrm{WNV}_{\mathrm{KUN}}$ is more prevalent in the Pilbara region (Figure 1) [27].

Sentinel chickens can also provide a means to evaluate implemented control measures. The Ilparpa Swamp located in the NT (Figure 1), provides an ideal breeding site for Cx. annulirostris mosquitoes. A drainage system in the Ilparpa Swamp was established in early 2002 as a mosquito reduction method. Since this intervention there have been no seroconversions in sentinel chickens to MVEV or $\mathrm{WNV}_{\mathrm{KUN}}$ and no human infections from these viruses in the NT [31], until the 2010-2011 wet season (November through March) [26]. 
Figure 1. Location of sentinel chicken flocks around Australia, 2010-2011, Adapted from CDI Annual Report Vol. 37 No. 1 2013, used by permission of the Australian Government [26]. Australian states are shown in red. WA-Western Australia, NTNorthern Territory, QLD—Queensland, NSW—New South Wales, VIC—Victoria, TAS Tasmania. Blue box represents the Kimberley region and the red box the Pilbara region. Inset represents sentinel chicken flocks in Victoria and New South Wales.



Aside from data generated from sentinel chickens, some state agencies also use meterological surveillance data, such as the Southern Oscillation Index and rainfall deciles using Forbes and Nicholls models to assess the risk of outbreaks. The Southern Oscillation index is an important indication of climatic fluctuations over the Indian and Pacific Oceans and is closely related to Eastern and Northern Australian rainfall. Therefore this index has been used to develop methods for predicting rainfall fluctuations over Australia and their biological implications. Both the Forbes and Nicholls MVEV climatic models indicated probable activity in south-eastern Australia for the 2010-2011 season (typically the spring/summer months from September through to February) [26,32,33]. Additional studies analyzing remote sensing data are being evaluated for the development of rainfall-based predictive models. One such model using Multi-satellite Precipitation Analysis data provides a state-of-the-art data source for the development of a rainfall-based predictive model for flavivirus activity in tropical WA [34]. In addition to fluctuations in rainfall, changes in temperature are also likely to affect the transmission of $\mathrm{WNV}_{\mathrm{KUN}}$. Distribution of mosquito species can be limited by 
temperatures, and thus tropical vectors are expected to move further south into currently cooler areas, when climate changes brings an increase in ambient temperature. Mosquitoes respond to local temperature increases in various ways and higher temperatures may lead to rapid development of larval populations, shorter times between bloodmeals, quicker incubation times for virus infections, and shorter life spans for adults [35]. Therefore, in a warmer climate, Cx. annulirostris mosquitoes might be expected to commence activity and reach high levels of abundance earlier, and maintain them longer; thus the season of arbovirus activity could be prolonged, with potentially greater levels of $\mathrm{WNV}_{\mathrm{KUN}}$ transmission. However, while the predicted increases in temperature associated with climate change should provide better conditions for mosquito species; these populations will require concomitant increase in rainfall to ensure larval habitat and to maintain humidity for adult survival. Providing appropriate vertebrate hosts are nearby, climate change associated with increased rainfall and temperature could lead to increased $\mathrm{WNV}_{\mathrm{KUN}}$ transmission [35].

\subsection{Epidemiology of Human Infections}

While human infections with $\mathrm{WNV}_{\mathrm{KUN}}$ are generally associated with mild symptoms, there has been a recent case that was associated with encephalitic symptoms [36]. A summary of the reported human cases and their location can be found in Table 1 . The number of cases attributed to $\mathrm{WNV}_{\mathrm{KUN}}$ has been lower than those reported for MVEV, except for 2004-2005 where four cases of $\mathrm{WNV}_{\mathrm{KUN}}$ were reported. Even during the 2011 outbreak, only one mild human case of $\mathrm{WNV}_{\mathrm{KUN}}$ was reported, despite over 1000 equine cases [2]. In comparison, 16 confirmed cases of MVEV were reported during 2011. In 2009-2010, 2 human cases of $\mathrm{WNV}_{\mathrm{KUN}}$ were reported, with one of these cases exhibiting encephalitic symptoms [28,36]. In 2007-2008 there was one human case involving a male tourist from Israel. This represents the first report of a laboratory confirmed imported WNV infection in Australia. This person was likely infected in the Middle East where WNV is endemic [27,37]. In general, human cases of $\mathrm{WNV}_{\mathrm{KUN}}$ are infrequent and mostly from northern Australia, with occasional infection and rare disease reported from southern regions of Australia (Figure 2, panel A).

Table 1. Number of confirmed cases of MVEV and $\mathrm{WNV}_{\mathrm{KUN}}$ in Australia, 2004-2011.

\begin{tabular}{|c|c|c|}
\hline \multirow{2}{*}{ Year } & MVEV & WNV KUN \\
\hline & Number of cases (location) & Number of cases (location) \\
\hline $2010-2011 *$ & 16 (2: NSW; 2: NT; 2: SA; 9: WA) & $1(\mathrm{NT})$ \\
\hline 2009-2010 \# & 0 & $2(1: \mathrm{NT} ; 1:$ QLD) \\
\hline $2008-2009^{€}$ & $4(2: \mathrm{NT} ; 2: \mathrm{WA})$ & 3 (1: NT; 2: QLD) \\
\hline $2007-2008^{\$}$ & $2(1: \mathrm{NSW} ; 1: \mathrm{WA})$ & $1(\mathrm{VIC})$ \\
\hline $2006-2007^{ \pm}$ & 0 & 0 \\
\hline $2005-2006^{\neq}$ & $1(\mathrm{WA})$ & 2 (WA) \\
\hline $2004-2005^{\S}$ & $2(1: \mathrm{NT} ; 1:$ QLD) & $4(3:$ QLD; $1:$ VIC) \\
\hline
\end{tabular}


Figure 2. Historical distribution of $\mathrm{WNV}_{\mathrm{KUN}}$ in Australia (A). Distribution of encephalitic horse cases in NSW during the 2011 outbreak (B). Dashed line indicates the Great Dividing Range. Adapted from [2].
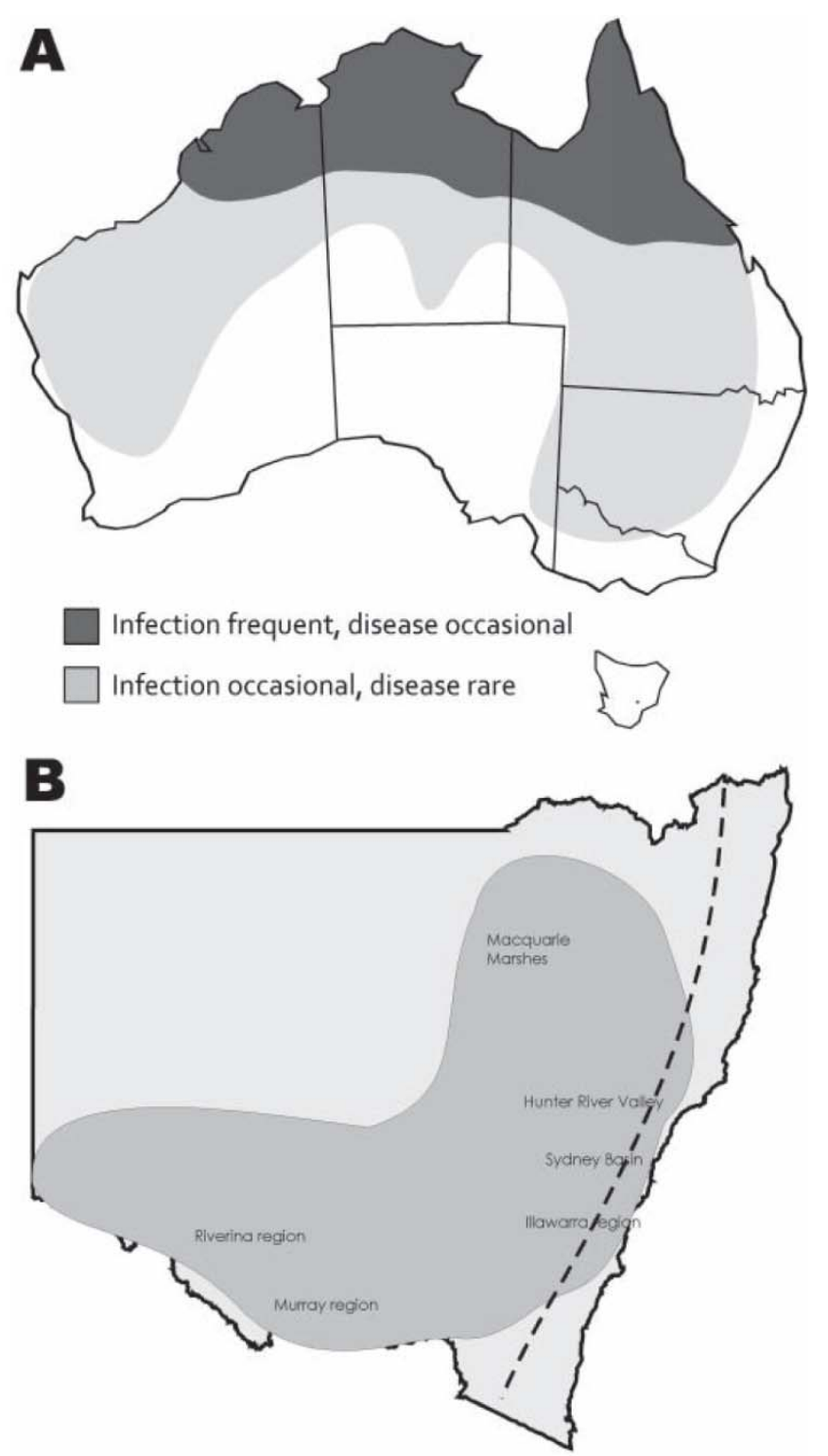

\section{Emergence of the First Virulent Strain in Australia to Cause an Outbreak}

The climatic conditions prior to 2011 for the NSW inland were above, to well above average rainfall for the entire second half of 2010, plus above average rainfall along the Murray River valley for the first quarter of 2011. The elevated rainfall led to increased vector populations with over 200,000 mosquitoes trapped at inland localities around NSW in 2011, being over six times that of the previous season [26]. Subsequently, a large number of arboviruses were isolated from NSW including seven WNV-like isolates from field-caught mosquitoes and one WNV-like virus from the brain of a deceased horse. All of these isolates were shown to be identical by sequence analysis and designated as $\mathrm{WNV}_{\mathrm{NSW} 2011}$, the virus responsible for the 2011 outbreak. Virus infections during this outbreak occurred in areas where $\mathrm{WNV}_{\mathrm{KUN}}$ had not been seen previously, including major inland cities in NSW (Figure 3). During the 2011 outbreak there were over 1,000 equine cases and a mortality rate of approximately 
$10 \%-15 \%$ of infected horses [2]. Clinical signs of $\mathrm{WNV}_{\mathrm{NSW} 2011}$ in horses were typical of that described for WNV in North America and included changes in temperament, in-coordination, ataxia, weakness, muscle paralysis and tremors [40]. The horse-derived $\mathrm{WNV}_{\mathrm{NSW} 2011}$ isolate was found to be genetically most closely related to the indigenous $\mathrm{WNV}_{\mathrm{KUN}}$, rather than other exotic WNV strains. However, at least two amino acid changes associated with increased virulence of $\mathrm{WNV}_{\mathrm{NY}} 9$, were present in the $\mathrm{WNV}_{\mathrm{NSW} 2011}$ sequence. Notably, $\mathrm{WNV}_{\mathrm{NSW} 2011}$ contained a glycosylated envelope protein at position 154 (N-Y-S) associated with neuroinvasion of WNV strains [41], as well as the phenylalanine residue at position 653 of the nonstructural protein 5 (NS5) that has been proposed to allow NS5 to be a potent antagonist of type I interferon-mediated JAK-STAT signaling [42]. However, the nonstructural protein 3 (NS3) motif, known to be responsible for increased bird virulence in $\mathrm{WNV}_{\mathrm{NY} 99}$ (Ala-Pro at amino acid 249) was not present in the $\mathrm{WNV}_{\text {NSW2011 }}$ genome consistent with a lack of bird morbidity or mortality during the outbreak. A study by Bingham and colleagues have determined that a species of Australian Crow, the Little Raven (Corvus mellori), common in southern Australia was resistant to WNV infection, even with $\mathrm{WNV}_{\mathrm{NY} 99}$ [43]. Therefore, species differences between Australian and American crows contributing to differing susceptibility to WNV infection suggests that the change in the NS3 gene may have a limited effect on virulence to local avian species. However, additional experiments testing the susceptibility of other Australian corvid species are also required.

$\mathrm{WNV}_{\mathrm{KUN}}$ isolates were obtained from equine and mosquito samples in NSW, VIC and SA and their genomes sequenced. $\mathrm{WNV}_{\mathrm{KUN}}$ isolates from 2011 were almost identical with the Victorian and NSW isolates sharing 99\% nucleotide identity [6]. Further analysis of $\mathrm{WNV}_{\mathrm{KUN}}$ isolates from 2011 has identified a substitution within the NS5 gene at residue $49(2577$; I $\rightarrow$ V) located in the methyl transferase domain compared to the prototype $\mathrm{WNV}_{\mathrm{KUN}}$ strain. This domain is involved in RNA capping and residue 49 forms part of the binding site for the monoclonal $5 \mathrm{H} 1$ in the $\alpha \mathrm{A} 3$ motif $[2,6,44]$. Whether this change in the virus contributes to virulence or is simply an evolutionary marker remains to be elucidated.

Cases of encephalitic horses were located throughout most of NSW, west of the Great Dividing Range, but also extending through the Hunter River valley region, Sydney Basin, and Illawarra coastal region (Figure 2B). Cases also occurred in other southern Australian states, including VIC and SA. Based on serological findings, the causative agents were $\mathrm{WNV}_{\mathrm{KUN}}, \mathrm{MVEV}$ and Ross River virus. In NSW, SA and WA, the majority of cases were due to $\mathrm{WNV}_{\mathrm{KUN}}$ infections, whereas in VIC, Ross River virus comprised more than half of all confirmed cases [26]. The largest number of serologically positive samples specific for $\mathrm{WNV}_{\mathrm{KUN}}$ came from NSW, while antibody positive samples were also identified from QLD, SA, VIC and WA. A large number of serological samples that were confirmed as flavivirus positive could not be clearly identified as MVEV or $\mathrm{WNV}_{\mathrm{KUN}}$ (see Figure 1, [8]) due to inconclusive findings during the analysis. These results suggest a need for re-evaluation of current diagnostic tests for MVEV and $\mathrm{WNV}_{\mathrm{KUN}}$ in the context of currently circulating virus strains. 
Figure 3. Distribution of horse cases during the 2011 outbreak. Adapted from [45].

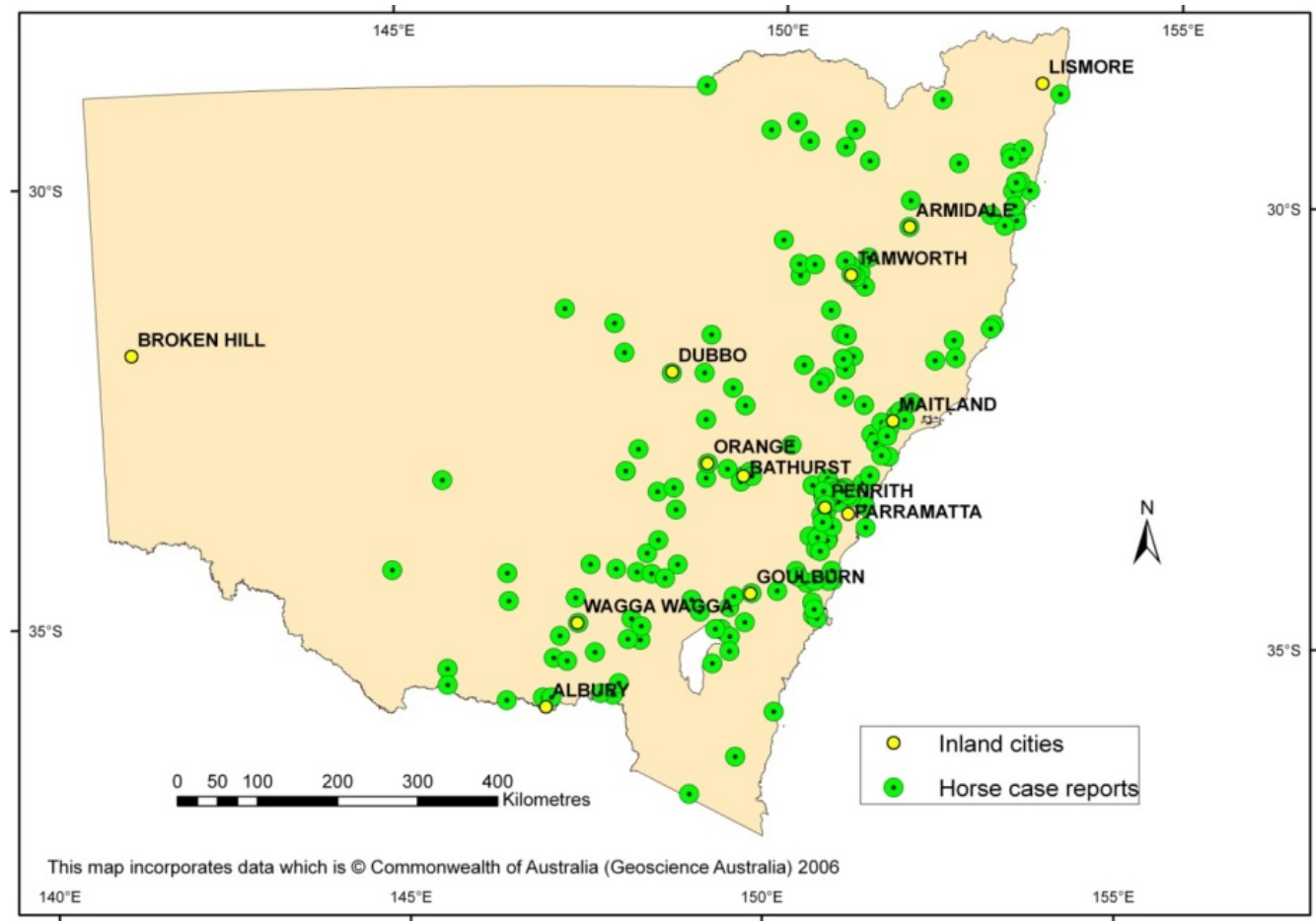

Another interesting epidemiological feature of the $\mathrm{WNV}_{\mathrm{NSW} 2011}$ outbreak was the detection of $\mathrm{WNV}_{\mathrm{KUN}}$ east of the Great Dividing Range in NSW. Indeed, $\mathrm{WNV}_{\mathrm{NSW} 2011}$ was detected despite relatively small mosquito populations in many of these areas, suggesting that the virus was transmitted more efficiently between mosquito vectors and mammalian hosts. Despite the abundance of $\mathrm{WNV}_{\mathrm{KUN}}$ isolates from $C x$. annulirostris mosquitoes in the past, it has been demonstrated that this mosquito has a relatively poor transmission rate in the laboratory [46]. Therefore, it has been suggested that the ability of this species to reach high population densities under optimal conditions deems it the primary $\mathrm{WNV}_{\mathrm{KUN}}$ vector in Australia [14]. In light of relatively small mosquito populations in major urban areas during the 2011 outbreak, it seems likely that other mosquito species aside from Cx. annulirostris contributed to transmission of $\mathrm{WNV}_{\mathrm{NSW} 2011}$. Furthermore, a previous study by Jansen et al., demonstrated that while $C x$. annulirostis gave a overall high level of vector competence for $\mathrm{WNV}_{\mathrm{NY} 99}$; there was intraspecific variation between populations, with mosquitoes collected from Brisbane (south-east QLD) appearing to be less efficient vectors compared to populations collected from Sydney (NSW) and Cairns (Northern QLD) [47]. This was also the case for $\mathrm{WNV}_{\mathrm{KUN}}$ in an older study [46]. Intraspecies variation may contribute to differences seen in $\mathrm{WNV}_{\mathrm{NSW} 2011}$ transmission in different areas during the outbreak.

Several studies have identified the presence of insect-specific flaviviruses (ISFs) that are maintained in nature in the absence of a vertebrate host [48-51]. While these viruses have not been associated with disease in humans, mosquitoes persistently infected with ISFs show an altered ability to transmit medically significant viruses, such as WNV [52,53]. In Australia, a novel insect-specific virus named Palm Creek virus, has recently been shown to inhibit the replication of $\mathrm{WNV}_{\mathrm{KUN}}$ in vitro [54]. Therefore, persistent infection of some populations of mosquitoes in Australia with ISFs may affect the transmission of $\mathrm{WNV}_{\mathrm{NSW} 2011}$. This theory needs further investigation. 
Historically wading birds, such as herons and egrets have been implicated as the natural reservoirs of $\mathrm{WNV}_{\mathrm{KUN}}[55,56]$. However, $\mathrm{WNV}_{\mathrm{NSW} 2011}$ may have adapted to additional bird species common to Australia that have not previously been involved in $\mathrm{WNV}_{\mathrm{KUN}}$ transmission, such as the house sparrow (Passer domesticus), that has been shown to be a competent reservoir for WNV in the USA [57]. The Australian white Ibis (Threskiornis molucca) has also been shown to be a reservoir of zoonotic pathogens, including flaviviruses [58] and therefore could have been involved in the transmission of $\mathrm{WNV}_{\mathrm{NSW} 2011}$.

Wild rabbits have been proposed as possible candidates for a cryptic host during the $\mathrm{WNV}_{\mathrm{NSW} 2011}$ outbreak based on observations of large herds of rabbits during 2011 (Peter Kirkland, personal communication). Feral rabbits have been demonstrated to develop a high viraemia following infection with MVEV [59] and Eastern cotton rabbits infected with $\mathrm{WNV}_{\mathrm{NY} 99}$ have been shown to develop sufficient viraemia to infect mosquitoes [60]. Preliminary studies evaluating the rabbit as a potential host of $\mathrm{WNV}_{\mathrm{NSW} 2011}$ have identified a low but sustained viramia in these animals [61]. While a high level of viraemia is generally required for active transmission, studies with Japanese encephalitis virus has demonstrated that despite a low level viraemia in inoculated flying foxes, infection of mosquitoes feeding on these animals still occurred [62]. In addition, differences between feral and lab bred animals and their susceptibility to WNV infection needs to be considered. Another possibility that warrants investigation is that feral animals may already be infected with another microbial agent, which may enhance the transmissibility of $\mathrm{WNV}_{\mathrm{NSW} 2011}$. Other mammals are likely to contribute to the transmission of $\mathrm{WNV}_{\mathrm{NSW} 2011}$. Domestic cats may represent a potential reservoir in urban transmission of $\mathrm{WNV}_{\mathrm{NSW} 2011}$, as the peak viraemia observed in cats infected with $\mathrm{WNV}_{\mathrm{NY} 99}$ may be high enough to infect mosquitoes at low efficiency [63]. A comprehensive evaluation of Australian mammals for the presence of $\mathrm{WNV}_{\mathrm{KUN}}$-specific antibodies would provide some indication of possible mammalian hosts.

Despite the emergence of a new virulent strain in 2011, virus transmission and disease occurrence did not continue into 2012 and since then only a few equine and human infections have been reported. Reasons for this could be sub-optimal environmental conditions, such as less than average rainfall preventing large populations of $C x$. annulirostris, pre-existing antibodies to $\mathrm{WNV}_{\mathrm{NSW} 2011}$ or the presence of an undefined vertebrate host (such as the rabbit). An isolate of $\mathrm{WNV}_{\mathrm{KUN}}$ obtained from mosquitoes collected during 2012 was recently assessed for virulence in an established murine model. The 2012 strain shows similar levels of virulence to $\mathrm{WNV}_{\mathrm{NSW} 2011}$ in mice [64], suggesting that the risk of further disease outbreaks to Australia remains.

Another unusual feature of the Australian outbreak was the absence of severe human cases, unlike what was seen during the on-going North American outbreak. This observation has sparked more questions as to the potential for new strains of $\mathrm{WNV}_{\mathrm{KUN}}$ to emerge and cause human disease. The emergence of $\mathrm{WNV}_{\mathrm{NSW} 2011}$ demonstrates the changing epidemiology of $\mathrm{WNV}_{\mathrm{KUN}}$ in Australia from a relatively benign to highly virulent virus and has led to follow-up studies investigating the origin and virulence of $\mathrm{WNV}_{\mathrm{NSW} 2011}$ compared to contemporary and historical strains of $\mathrm{WNV}_{\mathrm{KUN}}$. 


\section{Evaluation of Virulence of Contemporary and Historical WNV $\mathrm{KUN}_{\mathrm{N}}$ Strains}

A collection of $\mathrm{WNV}_{\mathrm{KUN}}$ strains isolated between 1960 and 2012 were tested for virulence in a young adult mouse model and their full-length genome sequences analysed to identify possible virulence motifs. In an attempt to elucidate the likely origin of the virulent $\mathrm{WNV}_{\mathrm{NSW} 2011}$ strain, isolates from both eastern and western Australia were tested. All five WA isolates were attenuated in the mouse model, whereas two of the strains from eastern Australia showed similar levels of virulence to


would suggest that virulent strains of $\mathrm{WNV}_{\mathrm{KUN}}$ have been circulating in eastern Australia.

$\mathrm{WNV}_{\mathrm{NSW} 2011}$, along with contemporary and historical $\mathrm{WNV}_{\mathrm{KUN}}$ strains were antigenically typed using a panel of monoclonal antibodies previously shown to differentiate between strains of $\mathrm{WNV}_{\mathrm{KUN}}$ and other WNVs [5,44,65-68]. Antigenic analysis confirmed that $\mathrm{WNV}_{\mathrm{NSW} 2011}$ was most closely related to Australian $\mathrm{WNV}_{\mathrm{KUN}}$ strains and likely emerged from currently circulating strains, rather than the introduction of an exotic WNV strain [2]. The binding profiles of these mAbs to contemporary $\mathrm{WNV}_{\mathrm{KUN}}$ strains confirmed that all strains tested closely resembled the prototype $\mathrm{WNV}_{\mathrm{KUN}}$ strain [64]. Interestingly, $\mathrm{WNV}_{\mathrm{KUN}}$ strains isolated after 2003, including $\mathrm{WNV}_{\mathrm{NSW} 2011}$, were no longer recognised by the mAb that binds the $\alpha \mathrm{A} 3$ motif (residues 39-53) in the MTase domain of NS5 [44]. The $\alpha \mathrm{A} 3$ motif has not been associated with virulence and this binding pattern may represent an evolutionary marker for $\mathrm{WNV}_{\mathrm{KUN}}$ strains [64].

Glycosylation of the envelope protein has been associated with neuroinvasion by WNV strains [41]. This was consistent with previous studies that showed attenuated $\mathrm{WNV}_{\mathrm{KUN}}$ isolates from Australia contained an unglycosylated envelope protein $[2,65]$. However, the passage history of $\mathrm{WNV}_{\mathrm{KUN}}$ has since been shown to significantly affect glycosylation, with extensive passaging through cell culture after isolation leading to a change in the glycosylation status of the envelope protein [65]. Indeed, recent analysis of low-passage contemporary $\mathrm{WNV}_{\mathrm{KUN}}$ strains revealed they all contained glycosylated E protein, regardless of their attenuation status [64]. While glycosylation of the envelope protein and motifs within the NS5 gene are both likely to contribute to the virulence of $\mathrm{WNV}_{\mathrm{NSW} 2011}$ compared to attenuated $\mathrm{WNV}_{\mathrm{KUN}}$ strains, it is clear that additional viral motifs are responsible for the enhanced virulence of the former. Comparison of full-length genome sequences of historical and contemporary $\mathrm{WNV}_{\mathrm{KUN}}$ strains will help identify these additional markers of virulence.

\section{Discussion}

Historically $\mathrm{WNV}_{\mathrm{KUN}}$ has been associated with only mild symptoms in humans and horses. However, under optimal environmental conditions, a newly emerged $\mathrm{WNV}_{\mathrm{KUN}}$ strain was able to cause an unprecedented outbreak of equine encephalitis in south-eastern Australia. While this outbreak was short-lived, virulent strains of $\mathrm{WNV}_{\mathrm{KUN}}$ circulate in Australia and will continue to pose a risk to humans and animals. An unexpected feature of the 2011 epidemic was that, despite the large number of equine cases, no severe cases of human disease were reported in areas of intense viral activity. The reasons behind this unusual event could be pre-existing antibodies in the community, a trophism of the virus for equines or minimal contact between humans and infected mosquitoes carrying $\mathrm{WNV}_{\mathrm{NSW} 2011}$. However it seems unlikely that pre-existing antibody against $\mathrm{WNV}_{\mathrm{KUN}}$ could explain the lack of 
human cases during the 2011 outbreak since a recent study found a very low prevelance of $\mathrm{WNV}_{\mathrm{KUN}}$ antibodies in VIC [69]. $\mathrm{WNV}_{\mathrm{NSW} 2011}$ infections was identified in areas in which $\mathrm{WNV}_{\mathrm{KUN}}$ is generally not associated, especially coastal cites east of the Great Dividing range. This change in epidemiology would suggest that an additional vertebrate host might be involved, which initiated studies into the possibility that rabbits may represent this alternative host. Preliminary studies have identified a low, but sustained viraemia in $\mathrm{WNV}_{\mathrm{NSW} 2011}$-infected rabbits, suggesting these animals may play a role in virus transmission [61].

WNV is estimated to have infected $\sim 4$ million humans in the United States (US), causing over 37,000 clinical infections, including 16,196 neuroinvasive disease cases and 1,443 deaths reported to the Centers for Disease Control and Prevention between 1999 and 2012 [70]. For a recent review of WNV focusing on North America and human disease, the reader is referred to Petersen et al. [71].

WNV has become endemic in all mainland states of the US, as well as all Canadian provinces since 1999 and is maintained in the US in a bird-mosquito-bird transmission cycle. North American strains of WNV (NA WNV) have been detected in 65 different mosquito species representing 10 different genera [72]. However only a few Culex mosquito species are responsible for the majority of transmission including $C x$. pipiens, $C x$. quinquefasciatus and $C x$. tarsalis [71]. Cx. quinquefasciatus is also widely distributed in both rural and urban habitats in Australia and is thought to be ornithophilic with bird feeding behavior having been documented [24,73]. Cx. quinquefasciatus populations collected in Australia were evaluated and shown to be highly competent for $\mathrm{WNV}_{\mathrm{NY} 99}$ [47]. Therefore, $C x$. quinquefasciatus could have been involved in urban transmission of $\mathrm{WNV}_{\mathrm{NSW} 2011}$. Other Australian members of the Culex pipiens group [74], including Cx. molestus, Cx. australicus and Cx. globocoxitus would also be other valid candidates contributing to transmission of $\mathrm{WNV}_{\mathrm{NSW} 2011}$.

Numerous passerine birds (perching birds of the order Passeriformes) develop sufficient viraemia following $\mathrm{WNV}_{\mathrm{NY} 99}$ infection to efficiently infect mosquitoes feeding upon them and therefore are competent amplifying hosts [57]. Furthermore, American crows (Corvus brachyrhynchos), blue jays (Cyanocitta cristata) and greater sage-grouse (Centrocercus urophasianus) completely succumb to infection with a $100 \%$ mortality rate $[57,75,76]$. While the Australian Crow (Little Raven-Corvus mellori) was resistant to lethal infection with $\mathrm{WNV}_{\mathrm{NY} 99}$ [43], birds are still likely to play a role in the transmission of $\mathrm{WNV}_{\mathrm{NSW} 2011}$. An evaluation of sera collected from different bird species where extensive $\mathrm{WNV}_{\mathrm{NSW} 2011}$ activity occurred, may provide clues as to particular species that could be involved in virus transmission.

West Nile virus was first reported in the US in 1999 and to date three genotypes belonging to WNV lineage I have been described; NY99, WN02 and SW/WN03. The NY99 genotype includes isolates from human cases from the US epidemic as well as bird and mosquito isolates collected in 1999. The WN02 genotype emerged in 2001, eventually displacing the NY99 genotype and is characterized by an amino acid change from valine to alanine at position 159 of the envelope protein. This amino acid substitution has been associated with earlier transmission and more efficient dissemination in Cx. pipiens and Cx. tarsalis mosquitoes as compared to the NY99 genotype [77]. However, this phenotype is still under debate [78]. The southwesten genotype, SW/WN03 was first identified in Arizona, Colorado and northern Mexico in 2003 and has subsequently spread to the Upper Texas Gulf Coast region [79]. Furthermore, ongoing dynamic circulation of WNV between the US and Mexico has been demonstrated [80]. While studies have demonstrated the emergence of new genotypes in the 
US, it is not clear whether these genetic changes will translate into phenotypic changes altering the risk of WNV to the human population. These studies from the US highlight the importance of continual surveillance of WNV to identify changes to the virus genome that could lead to phenotypic changes in the virus. On-going surveillance of $\mathrm{WNV}_{\mathrm{KUN}}$ isolates in Australia will also provide information as to whether virulent strains continue to circulate, as is the case with a $\mathrm{WNV}_{\mathrm{KUN}}$ isolate from 2012.

Another important lesson from the North American outbreak was the demonstration that WNV can be transmitted to humans via blood transfusion [81]. The study by Pealer and colleages demonstrated that using blood donor screening, recent donors with a low level viraemia who had not yet developed WNV-specific antibodies could efficiently transmit the infection. In light of these findings, national blood donor screening using nucleic acid tests were initiated in 2003 to ensure transfusion safety [82]. Newly emerging virulent strains of $\mathrm{WNV}_{\mathrm{KUN}}$ could also pose a similar threat to the safety of the Australian blood supply. Future studies are required to evaluate the risk that newly emerging strains pose to transfusion safety in Australia and whether extensive donor screening is required.

\section{Conclusions and Future Directions}

The epidemiology and ecology of $\mathrm{WNV}_{\mathrm{KUN}}$ has changed in recent years with $\mathrm{WNV}_{\mathrm{KUN}}$ no longer a naturally attenuated virus, but one that can and has caused a large outbreak of equine encephalitis and therefore warrants new investigations to evaluate genetic and phenotype changes in currently circulating strains. On-going studies will address the seroprevalence of $\mathrm{WNV}_{\mathrm{KUN}}$-specific antibodies in humans and virulence motifs within $\mathrm{WNV}_{\mathrm{NSW} 2011}$ that may restrict this virus to equines. Furthermore, future studies need to consider parameters affecting the virus, hosts and vectors separately and in concert in order to better understand risk factors predisposing to disease outbreaks. Further sequence analysis of all contemporary and historical strains of $\mathrm{WNV}_{\mathrm{KUN}}$ will help elucidate the key residues responsible for enhanced virulence of $\mathrm{WNV}_{\mathrm{NSW} 2011}$. Preliminary studies comparing contemporary, historical and known virulent strains of $\mathrm{WNV}_{\mathrm{KUN}}$ have identified possible putative virulence determinants and/or evolutionary markers, including the $\alpha \mathrm{A} 3$ motif. Given the close genetic relationship between NA WNV strains and $\mathrm{WNV}_{\mathrm{KUN}}$, results from these ongoing studies will be directly relevant for currently circulating strains in the US. These studies will provide valuable information evaluating the true risk of WNV in a medical and veterinary context.

\section{Acknowledgments}

I would like to thank Cheryl Johansen for providing sentinel chicken surveillance data from WA; Roy Hall and Helle Bielefeldt-Ohmann for useful discussion and critical feedback on the manuscript.

\section{Conflict of Interest}

The author declares no conflict of interest. 


\section{References}

1. Danis, K.; Papa, A.; Theocharopoulos, G.; Dougas, G.; Athanasiou, M.; Detsis, M.; Baka, A.; Lytras, T.; Mellou, K.; Bonovas, S.; et al. Outbreak of West Nile virus infection in Greece, 2010. Emerg. Infect. Dis. 2011, 17, 1868-1872.

2. Frost, M.J.; Zhang, J.; Edmonds, J.H.; Prow, N.A.; Gu, X.; Davis, R.; Hornitzky, C.; Arzey, K.E.; Finlaison, D.; Hick, P.; et al. Characterization of virulent West Nile virus Kunjin strain, Australia, 2011. Emerg. Infect. Dis. 2012, 18, 792-800.

3. Garcia-Bocanegra, I.; Jaén-Téllez, J.A.; Napp, S.; Arenas-Montes, A., Fernández-Morente, M.; Fernández-Molera, V.; Arenas, A. West Nile fever outbreak in horses and humans, Spain, 2010. Emerg. Infect. Dis. 2011, 17, 2397-2399.

4. Kutasi, O.; Bakonyi, T.; Lecollinet, S.; Biksi, I.; Ferenczi, E.; Bahuon, C.; Sardi, S.; Zientara, S.; Szenci, O. Equine encephalomyelitis outbreak caused by a genetic lineage 2 West Nile virus in Hungary. J. Vet. Intern. Med. 2011, 25, 586-591.

5. Lanciotti, R.S.; Roehrig, J.T.; Deubel, V.; Smith, J.; Parker, M.; Steele, K.; Crise, B.; Volpe, K.E.; Crabtree, M.B.; Scherret, J.H.; et al. Origin of the West Nile virus responsible for an outbreak of encephalitis in the northeastern United States. Science 1999, 286, 2333-2337.

6. Mann, R.A.; Fegan, M.; O’Riley, K.; Motha, J.; Warner, S.; Molecular characterization and phylogenetic analysis of Murray Valley encephalitis virus and West Nile virus (Kunjin subtype) from an arbovirus disease outbreak in horses in Victoria, Australia, in 2011. J. Vet. Diagn. Invest. 2013, 25, 35-44.

7. Murray, K.O.; Mertens, E.; Despres, P. West Nile virus and its emergence in the United States of America. Vet. Res. 2010, 41, doi:10.1051/vetres/2010039.

8. Roche, S.E.; Wicks, R.; Garner, M.G.; East, I.J.; Paskin, R.; Moloney, B.J.; Carr, M.; Kirkland, P. Descriptive overview of the 2011 epidemic of arboviral disease in horses in Australia. Aust. Vet. J. 2013, 91, 5-13.

9. Spissu, N.; Panichi, G.; Montisci, A.; Fiore, F. West Nile virus outbreak in Sardinia, Italy, in 2011. J. Infect. Dev. Ctries. 2013, 7, 6-9.

10. Mackenzie, J.S.; Williams, D.T. The zoonotic flaviviruses of southern, south-eastern and eastern Asia, and Australasia: the potential for emergent viruses. Zoonoses Public Health 2009, 56, 338-356.

11. May, F.J.; Davis, C.T.; Tesh, R.B.; Barrett, A.D. Phylogeography of West Nile virus: from the cradle of evolution in Africa to Eurasia, Australia, and the Americas. J. Virol. 2011, 85, 2964-2974.

12. Badman, R.; Campbell, J.; and Aldred, J. Arbovirus infection in horses-Victoria. Commun. Dis. Intell. 1984, 17, 5-6.

13. Flynn, L.M.; Coelen, R.J.; Mackenzie, J.S. Kunjin virus isolates of Australia are genetically homogeneous. J. Gen. Virol. 1989, 70, 2819-2824.

14. Hall, R.A.; Broom, A.K.; Smith, D.W.; Mackenzie, J.S. The ecology and epidemiology of Kunjin virus. Curr. Top. Microbiol. Immunol. 2002, 267, 253-269.

15. Marshall, I. Murray Valley and Kunjin Encpehalitis. In The Arboviruses: Epidemiology and Ecology; Monath, T.P., Ed.; CRC Press: Boca Raton, FL, USA, 1988; pp. 151-189.

16. Mackenzie, J.S.; Lindsay, M.D.; Coelen, R.J.; Broom, A.K.; Hall, R.A.; Smith, D.W. Arboviruses causing human disease in the Australasian zoogeographic region. Arch. Virol. 1994, 136, 447-467. 
17. Prow, N.A.; Hall, R.A.; Lobigs, M. Murray Valley Encephalitis Virus. In Neuroviral Infections; Singh, S.K., Ruzek, D., Eds.; Taylor \& Francis Group, Boca Raton, FL, USA, 2012; pp. 167-192.

18. Knox, J.; Cowan, R.U.; Doyle, J.S.; Ligtermoet, M.K.; Archer, J.S.; Burrow, J.N.; Tong, S.Y.; Currie, B.J.; Mackenzie, J.S.; Smith, D.W.; et al. Murray Valley encephalitis: A review of clinical features, diagnosis and treatment. Med. J. Aust. 2012, 196, 322-326.

19. Gordon, A.N.; Marbach, C.R.; Oakey, J.; Edmunds, G.; Condon, K.; Diviney, S.M.; Williams, D.T.; Bingham, J. Confirmed case of encephalitis caused by Murray Valley encephalitis virus infection in a horse. J. Vet. Diagn. Invest. 2012, 24, 431-436.

20. Holmes, J.M.; Gilkerson, J.R.; El Hage, C.M.; Slocombe, R.F.; Muurlink, M.A. Murray Valley encephalomyelitis in a horse. Aust. Vet. J. 2012, 90, 252-254.

21. Prow, N.A.; Tan, C.S.E.; Wang, W.; Hobson-Peters, J.; Kidd, L.; Barton, A.; Wright, J.; Hall, R.A.; Bielefeldt-Ohmann, H. Natural exposure of horses to mosquito-borne flaviviruses in South-East Queensland, Australia. Int. J. Environ. Res. Public Health 2013, 10, 4432-4443.

22. Russell, R.C. Arboviruses and their vectors in Australia: An update on the ecology and epidemiology of some mosquito-borne arboviruses. Rev. Med. Vet. Entomol. 1995, 83, 141-158.

23. Broom, A.K.; Mackenzie, J.S.; Lindsay, M.D.; Wright, A.E. Epidemiology of Murray Valley encephalitis and Kunjin viruses in Western Australia. Arbovirus Res. Aust. 1989, 5, 14-18.

24. Kay, B.H.; Boreham, P.F.; Fanning, I.D. Host-feeding patterns of Culex annulirostris and other mosquitoes (Diptera: Culicidae) at Charleville, southwestern Queensland, Australia. J. Med. Entomol. 1985, 22, 529-535.

25. Australian Government Department of Health and Ageing. National Arbovirus and Malaria Advisory Committee (NAMAC) Annual Reports. Available online: http://www.health.gov.au/ internet/main/publishing.nsf/Content/cda-arboanrep.htm (accessed on 1 Aug 2013).

26. Knope, K.; Whelan, P.; Smith, D.; Johansen, C.; Moran, R.; Doggett, S.; Sly, A.; Hobby, M.; Kurucz, N.; Wright, P.; et al. Arboviral diseases and malaria in Australia, 2010-11: Annual report of the National Arbovirus and Malaria Advisory Committee. Commun. Dis. Intell. Q. Rep. 2013, 37, E1-E20.

27. Fitzsimmons, G.J.; Wright, P.; Johansen, C.A.; Whelan, P.I. Arboviral diseases and malaria in Australia, 2007/08: Annual report of the National Arbovirus and Malaria Advisory Committee. Commun. Dis. Intell. Q. Rep. 2009, 33, 155-169.

28. Wright, P.; Fitzsimmons, G.J.; Johansen, C.A.; Whelan, P.I. Arboviral diseases and malaria in Australia, 2009-10: Annual report of the National Arbovirus and Malaria Advisory Committee. Commun. Dis. Intell. Q. Rep. 2012, 36, 70-81.

29. Liu, C.; Begg, K.; Johansen, C.; Whelan, P.; Kurucz, N.; Melville, L. Communicable diseases network Australia National Arbovirus And Malaria Advisory Committee annual report, 2006-07. Commun. Dis. Intell. Q. Rep. 2008, 32, 31-47.

30. Liu, C.; Johansen, C.; Kurucz, N.; Whelan, P. Communicable diseases network Australia National Arbovirus And Malaria Advisory Committee annual report, 2005-06. Commun. Dis. Intell. Q. Rep. 2006, 30, 411-429.

31. Jacups, S.; Kurucz, N.; Whitters, R.; Whelan, P. Habitat modification for mosquito control in the Ilparpa Swamp, Northern Territory, Australia. J. Vector Ecol. 2011, 36, 292-299. 
32. Forbes, J.A. Murray Valley Encephalitis 1974: Also the Epidemic Variance Since 1914 and Predisposing Rainfall Patterns; Australasian Medical Publishing Company: Sydney, Australia, 1978.

33. Nicholls, N. A method for predicting Murray Valley encephalitis in southeast Australia using the Southern Oscillation. Aust. J. Exp. Biol. Med. Sci. 1986, 64, 587-594.

34. Schuster, G.; Ebert, E.E.; Stevenson, M.A.; Corner, R.J.; Johansen, C.A. Application of satellite precipitation data to analyse and model arbovirus activity in the tropics. Int. J. Health Geogr. 2011, 10, doi:10.1186/1476-072X-10-8.

35. Russell, R.C. Mosquito-borne arboviruses in Australia: The current scene and implications of climate change for human health. Int. J. Parasitol. 1998, 28, 955-969.

36. Kurucz, N.; Gray, T.J.; Burrow, J.; Whelan, P. A confirmed case of Kunjin virus disease encephalitis acquired in rural Darwin, NT - The mosquito story. North. Territ. Dis. Control Bull. 2010, 17, 5-10.

37. Rogers, B.A.; Hueston, L.; Ratnam, I. Imported West Nile virus encephalitis in an Israeli tourist. Med. J. Aust. 2009, 191, 232-234.

38. Fitzsimmons, G.J.; Wright, P.; Johansen, C.A.; Whelan, P.I. Arboviral diseases and malaria in Australia, 2008-09: Annual report of the National Arbovirus and Malaria Advisory Committee. Commun. Dis. Intell. Q. Rep. 2010, 34, 225-240.

39. Liu, C.; Broom, A.K.; Kurucz, N.; Whelan, P.I. Communicable Diseases Network Australia: National Arbovirus and Malaria Advisory Committee annual report 2004-05. Commun. Dis. Intell. Q. Rep. 2005, 29, 341-357.

40. Ostlund, E.N.; Crom, R.L.; Pedersen, D.D.; Johnson, D.J.; Williams, W.O.; Schmitt, B.J. Equine West Nile encephalitis, United States. Emerg. Infect. Dis. 2001, 7, 665-669.

41. Beasley, D.W.; Li, L.; Suderman, M.T.; Barrett, A.D. Mouse neuroinvasive phenotype of West Nile virus strains varies depending upon virus genotype. Virology 2002, 296, 17-23.

42. Laurent-Rolle, M.; Boer, E.F.; Lubick, K.J.; Wolfinbarger, J.B.; Carmody, A.B.; Rockx, B.; Liu, W.; Ashour, J.; Shupert, W.L.; Holbrook, M.R.; et al. The NS5 protein of the virulent West Nile virus NY99 strain is a potent antagonist of type I interferon-mediated JAK-STAT signaling. J. Virol. 2010, 84, 3503-3515.

43. Bingham, J.; Lunt, R.A.; Green, D.J.; Davies, K.R.; Stevens, V.; Wong, F.Y. Experimental studies of the role of the little raven (Corvus mellori) in surveillance for West Nile virus in Australia. Aust. Vet. J. 2010, 88, 204-210.

44. Hall, R.A.; Tan, S.E.; Selisko, B.; Slade, R.; Hobson-Peters, J.; Canard, B.; Hughes, M.; Leung, J.Y.; Balmori-Melian, E.; Hall-Mendelin, S.; et al. Monoclonal antibodies to the West Nile virus NS5 protein map to linear and conformational epitopes in the methyltransferase and polymerase domains. J. Gen. Virol. 2009, 90, 2912-2922.

45. Walker, B. Kunjin virus neurological disease in horses. NSW Gov. 2012. Available online: http://www.dpi.nsw.gov.au/_data/assets/pdf_file/0004/417325/Kunjin-virus-neurological-diseasein-horses.pdf (accessed on 15 Aug 2013).

46. Kay, B.H.; Fanning, I.D.; Carley, J.G. The vector competence of Australian Culex annulirostris with Murray Valley encephalitis and Kunjin viruses. Aust. J. Exp. Biol. Med. Sci. 1984, 62, 641-650. 
47. Jansen, C.C.; Webb, C.E.; Northill, J.A.; Ritchie, S.A.; Russell, R.C.; Van den Hurk, A.F. Vector competence of Australian mosquito species for a North American strain of West Nile virus. Vector Borne Zoonotic Dis. 2008, 8, 805-811.

48. Crabtree, M.B.; Sang, R.C.; Stollar, V.; Dunster, L.M.; Miller, B.R. Genetic and phenotypic characterization of the newly described insect flavivirus, Kamiti River virus. Arch. Virol. 2003, $148,1095-1118$.

49. Hoshino, K.; Isawa, H.; Tsuda, Y.; Yano, K.; Sasaki, T.; Yuda, M.; Takasaki, T.; Kobayashi, M.; Sawabe, K. Genetic characterization of a new insect flavivirus isolated from Culex pipiens mosquito in Japan. Virology 2007, 359, 405-414.

50. Cook, S.; Moureau, G.; Harbach, R.E.; Mukwaya, L.; Goodger, K.; Ssenfuka, F.; Gould, E.; Holmes, E.C.; de Lamballerie, X. Isolation of a novel species of flavivirus and a new strain of Culex flavivirus (Flaviviridae) from a natural mosquito population in Uganda. J. Gen. Virol. 2009, 90, 2669-2678.

51. Crabtree, M.B.; Nga, P.T.; Miller, B.R. Isolation and characterization of a new mosquito flavivirus, Quang Binh virus, from Vietnam. Arch. Virol. 2009, 154, 857-860.

52. Bolling, B.G.; Olea-Popelka, F.J.; Eisen, L.; Moore, C.G.; Blair, C.D. Transmission dynamics of an insect-specific flavivirus in a naturally infected Culex pipiens laboratory colony and effects of co-infection on vector competence for West Nile virus. Virology, 2012, 427, 90-97.

53. Kent, R.J.; Crabtree, M.B.; Miller, B.R. Transmission of West Nile virus by Culex quinquefasciatus say infected with Culex Flavivirus Izabal. PLoS Negl. Trop. Dis. 2010, 4, doi:10.1371/journal.pntd.0000671.

54. Hobson-Peters, J.; Yam, A.W.; Lu, J.W.; Setoh, Y.X.; May, F.J.; Kurucz, N.; Walsh, S.; Prow, N.A.; Davis, S.S.; Weir, R.; et al. A new insect-specific flavivirus from northern Australia suppresses replication of West Nile virus and Murray Valley encephalitis virus in co-infected mosquito cells. PLoS One 2013, 8, doi:10.1371/journal.pone.0056534.

55. Marshall, I.D.; Brown, B.K.; Keith, K.; Gard, G.P.; Thibos, E. Variation in arbovirus infection rates in species of birds sampled in a serological survey during an encephalitis epidemic in the Murray Valley of South-eastern Australia, February 1974. Aust. J. Exp. Biol. Med. Sci. 1982, 60, 471-478.

56. Russell, R.C.; Kay, B.H. Medical entomology: changes in the spectrum of mosquito-borne disease in Australia and other vector threats and risks, 1972-2004. Aust. J. Entomol. 2004, 43, 271-282.

57. Komar, N.; Langevin, S.; Hinten, S.; Nemeth, N.; Edwards, E.; Hettler, D.; Davis, B.; Bowen, R.; Bunning, M. Experimental infection of North American birds with the New York 1999 strain of West Nile virus. Emerg. Infect. Dis. 2003, 9, 311-322.

58. Epstein, J.H.; McKee, J.; Shaw, P.; Hicks, V.; Micalizzi, G.; Daszak, P.; Kilpatrick, A.M.; Kaufman, G. The Australian White Ibis (Threskiornis molucca) as a reservoir of zoonotic and livestock pathogens. EcoHealth 2007, 3, 290-298.

59. Kay, B.H.; Hall, R.A.; Fanning, I.D.; Young, P.L. Experimental infection with Murray Valley encephalitis virus: Galahs, sulphur-crested cockatoos, corellas, black ducks and wild mice. Aust. J. Exp. Biol. Med. Sci. 1985, 63, 599-606.

60. Tiawsirisup, S.; Platt, K.B.; Tucker, B.J.; Rowley, W.A. Eastern cottontail rabbits (Sylvilagus floridanus) develop West Nile virus viremias sufficient for infecting select mosquito species. Vector Borne Zoonotic Dis. 2005, 5, 342-350. 
61. Suen, W; Prow, N.A.; Wang, W.; Broad, N.; Hall, R.A.; Kirkland, P.D.; Bielefeldt-Ohmann, H. The establishment of a rabbit model to elucidate the mechanism of neuroinvasion by an emergent Australian West Nile virus. Unpublished work.

62. van den Hurk, A.F.; Smith, C.S.; Field, H.E.; Smith, I.L.; Northill, J.A.; Taylor, C.T.; Jansen, C.C.; Smith, G.A.; Mackenzie, J.S. Transmission of Japanese Encephalitis virus from the black flying fox, Pteropus alecto, to Culex annulirostris mosquitoes, despite the absence of detectable viremia. Am. J. Trop. Med. Hyg. 2009, 81, 457-462.

63. Austgen, L.E.; Bowen, R.A.; Bunning, M.L.; Davis, B.S.; Mitchell, C.J.; Chang, G.J. Experimental infection of cats and dogs with West Nile virus. Emerg. Infect. Dis. 2004, 10, 82-86.

64. Prow, N.A.; Edmonds J.H.; Setoh, Y.X.; Bielefeldt-Ohmann, H., Suen, W., Hobson-Peters, J.; van den Hurk, A.F.; Pyke, A.; Hall-Mendelin, S.; Warrilow, D.; et al. Investigating the origin of an emerging virulent strain of West Nile virus in Australia. Emerg. Infect. Dis. In preparation.

65. Adams, S.C.; Broom, A.K.; Sammels, L.M.; Hartnett, A.C.; Howard, M.J.; Coelen, R.J.; Mackenzie, J.S.; Hall, R.A. Glycosylation and antigenic variation among Kunjin virus isolates. Virology 1995, 206, 49-56.

66. Hall, R.A.; Scherret, J.H.; Mackenzie, J.S. Kunjin virus: An Australian variant of West Nile? Ann. N. Y. Acad. Sci. 2001, 951, 153-160.

67. Hobson-Peters, J.; Toye, P.; Sanchez, M.D.; Bossart, K.N.; Wang, L.F.; Clark, D.C.; Cheah, W.Y.; Hall, R.A. A glycosylated peptide in the West Nile virus envelope protein is immunogenic during equine infection. J. Gen. Virol. 2008, 89, 3063-3072.

68. Scherret, J.H.; Poidinger, M.; Mackenzie, J.S.; Broom, A.K.; Deubel, V.; Lipkin, W.I.; Briese, T.; Gould, E.A.; Hall, R.A. The relationships between West Nile and Kunjin viruses. Emerg. Infect. Dis. 2001, 7, 697-705.

69. Williams, S.A.; Richards, J.S.; Faddy, H.M.; Leydon, J.; Moran, R.; Nicholson, S.; Perry, F.; Paskin, R.; Catton, M.; Lester, R.; Mackenzie, J.S. Low seroprevalence of Murray Valley Encephalitis and Kunjin viruses in an opportunistic serosurvey, Victoria 2011. Aust. N. Z. J. Public Health 2013, 37, 427-433.

70. Centers for Disease Control and Prevention. West Nile Virus. Available online: http://www.cdc.gov/westnile/statsMaps/final.html (accessed on 1 September 2013).

71. Petersen, L.R.; Brault, A.C.; Nasci, R.S. West Nile virus: Review of the literature. JAMA 2013, 310, 308-315.

72. Centers for Disease Control and Prevention. Mosquito Species in Which West Nile Virus has been Detected, United States, 1999-2012. Available online: http://www.cdc.gov/westnile/ resources/pdfs/Mosquito\%20Species\%201999-2012.pdf (accessed on 1 September 2013).

73. Kay, B.H.; Boreham, P.F.L.; Williams, G.M. Host preferences and feeding patterns of mosquitoes at Kowanyama, Cape York Peninsula, northern Queensland. Bull. Entomol. Res. 1979, 69, 441-457.

74. Russell, R.C. A review of the status and significance of the species within the Culex pipiens group in Australia. J. Am. Mosq. Control. Assoc. 2012, 28, 24-27.

75. Clark, L.; Hall, J.; McLean, R.; Dunbar, M.; Klenk, K.; Bowen, R.; Smeraski, C.A. Susceptibility of greater sage-grouse to experimental infection with West Nile virus. J. Wildl. Dis. 2006, 42, $14-22$. 
76. McLean, R.G.; Ubico, S.R.; Docherty, D.E.; Hansen, W.R.; Sileo, L.; McNamara, T.S. West Nile virus transmission and ecology in birds. Ann. N Y Acad. Sci. 2001, 951, 54-57.

77. Moudy, R.M.; Meola, M.A.; Morin, L.L.; Ebel, G.D.; Kramer, L.D. A newly emergent genotype of West Nile virus is transmitted earlier and more efficiently by Culex mosquitoes. Am. J. Trop. Med. Hyg. 2007, 77, 365-370.

78. Anderson, J.F.; Main, A.J.; Cheng, G.; Ferrandino, F.J.; Fikrig, E. Horizontal and vertical transmission of West Nile virus genotype NY99 by Culex salinarius and genotypes NY99 and WN02 by Culex tarsalis. Am. J. Trop. Med. Hyg. 2012, 86, 134-139.

79. McMullen, A.R.; May, F.J.; Li, L.; Guzman, H.; Bueno, R., Jr.; Dennett, J.A.; Tesh, R.B.; Barrett, A.D. Evolution of new genotype of West Nile virus in North America. Emerg. Infect. Dis. 2011, 17, 785-793.

80. Mann, B.R.; McMullen, A.R.; Guzman, H.; Tesh, R.B.; Barrett, A.D. Dynamic transmission of West Nile virus across the United States-Mexican border. Virology 2013, 436, 75-80.

81. Pealer, L.N.; Marfin, A.A.; Petersen, L.R.; Lanciotti, R.S.; Page, P.L.; Stramer, S.L.; Stobierski, M.G.; Signs, K.; Newman, B.; Kapoor, H.; et al. Transmission of West Nile virus through blood transfusion in the United States in 2002. N Engl. J. Med. 2003, 349, 1236-1245.

82. Petersen, L.R.; Busch, M.P. Transfusion-transmitted arboviruses. Vox Sang. 2010, 98, 495-503.

(C) 2013 by the authors; licensee MDPI, Basel, Switzerland. This article is an open access article distributed under the terms and conditions of the Creative Commons Attribution license (http://creativecommons.org/licenses/by/3.0/). 